\title{
The Effects of Information Format and Shopping Task on Consumers' Online Shopping Behavior: A Cognitive Fit Perspective
}

\author{
WEIYIN HONG, JAMES Y.L. THONG, AND KAR YAN TAM
}

WeIYIN Hong is an Assistant Professor in the Department of Management Information Systems, University of Nevada, Las Vegas. She received her B.Sc. in Management Information Systems from Fudan University, China, and her Ph.D. in Information and Systems Management from the Hong Kong University of Science and Technology. Her research interest includes user acceptance of emerging technologies and human-computer interaction. Her work has appeared in Information Systems Research, Journal of Management Information Systems, Communications of the ACM, and International Journal of Human-Computer Studies.

JAMES Y.L. THONG is an Associate Professor in the Department of Information and Systems Management, School of Business and Management, Hong Kong University of Science and Technology. He received his Ph.D. in information systems from the National University of Singapore. His research on IT adoption and implementation, IT in small business, human-computer interaction, and computer ethics, has appeared in Communications of the ACM, European Journal of Information Systems, European Journal of Operational Research, IEEE Communications, Information \& Management, Information Processing \& Management, Information Systems Research, International Journal of Human-Computer Studies, Journal of Management Information Systems, Omega, and Telecommunications Policy. He is currently an Associate Editor for MIS Quarterly.

KAR YAN TAM is Professor of Information Systems and Associate Dean of the Business School at the Hong Kong University of Science and Technology. His current research interests include mobile commerce, human-computer interaction, and Web personalization. Dr. Tam's publications have appeared in Information Systems Research, Management Science, Journal of Management Information Systems, MIS Quarterly, and IEEE Transactions on Engineering Management. He is on the editorial board of a number of information systems journals. He is also currently Director of the Center for Electronic Commerce at HKUST. Dr. Tam has extensive consulting experience with major corporations, including Sun Microsystems, Symantec, and HSBC.

ABSTRACT: A feature central to the success of e-commerce Web sites is the design of an effective interface to present product information. However, the suitability of the prevalent information formats in supporting various online shopping tasks is not known. Using the cognitive fit theory as the theoretical framework, we developed a research model to investigate the fit between information format and shopping task, and exam-

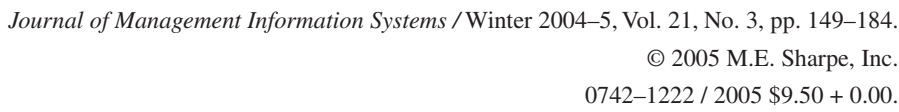


ine its influence on consumers' online shopping performance and perceptions of shopping experience. The competition for attention theory from the marketing literature and the scanpath theory from vision research were employed to support the analyses. An experiment was conducted to examine the effects of two types of information formats (list versus matrix) in the context of two types of shopping tasks (searching versus browsing). The results show that when there is a match between the information format and the shopping task, consumers can search the information space more efficiently and have better recall of product information. Specifically, the list format better supports browsing tasks, and the matrix format facilitates searching tasks. However, a match between the information format and the shopping task has no effect on cognitive effort or attitude toward using the Web site. Overall, this research supports the application of the cognitive fit theory to the study of Web interface design. It also demonstrates the value in integrating findings from cognitive science and vision research to understand the processes involved. As the information format has been shown to affect consumers' online shopping behavior, even when the information content is held constant, the practical implications for Web site designers include providing both types of information format on their Web sites and matching the appropriate information format to the individual consumer's task.

KEY WORDS AND PHRASES: B2C e-commerce, cognitive fit theory, competition for attention theory, e-commerce, e-tailing, information format, interface design, online shopping, scanpath theory, shopping task.

E-COMMERCE IS GROWING RAPIDLY with the proliferation of commercial Web sites and the increasing acceptance of online transactions by consumers. The global online trade is projected to reach $\$ 12.8$ trillion by 2006 , which comprises approximately 18 percent of total sales [21]. As a new marketing channel, the Internet differs from the traditional retail formats in many ways [3,12]. A unique characteristic of online shopping is that consumers cannot touch or smell the products, as they usually do in the traditional retail outlets, and have to base their judgments on the product information presented on the Web sites. As a consequence, Web interface design plays a significant role in affecting consumers' online shopping performance and attitude toward the Web site $[25,56,74]$. The rapid growth in e-commerce and the distinctiveness of this new marketing channel highlight the importance of understanding the effects of the Web interface on consumers' online shopping behavior.

A potential determinant of consumers' online shopping behavior is the information format, which refers to how information is presented and organized [16]. It was established in traditional information systems (IS) research that the information format can have a significant effect on users' information acquisition, processing, and decision-making performance [7, 37]. Similarly, in e-commerce, the information format of the Web site interface can be crucial. As the first stage of an electronic market transaction, the interface has received much attention from designers of commercial Web sites [66]. With the vast amount of product information available online, consumers very often learn about new products through the Internet, where the interface design of the Web sites plays a major role $[3,38]$. According to Lohse and Spiller: 
"Now more than ever, the promise of electronic commerce and online shopping will depend to a great extent upon the interface and how people interact with the computer" [42, p. 81]. While the information content of Web sites is an important determinant of successful Web sites [22, 43], it is unclear, given the same information content, whether the information format will have an effect on consumers' online shopping behavior; and if so, how. More importantly, it remains to be determined whether the effects of information format on online shopping behavior differ for consumers with different shopping tasks [29].

Some attempts have been made to classify online consumers in terms of the shopping tasks that they intend to perform on e-commerce Web sites (e.g., [9, 50, 64]). In general, there is a consensus that there are two major categories of online shopping tasks: searching tasks and browsing tasks $[13,58,75]$. In searching tasks, consumers have particular, known, and specific objectives (e.g., searching for a Canon Powershot S400 digital camera); whereas in browsing tasks, ${ }^{1}$ consumers only have general objectives (e.g., browsing for a digital camera). This distinction can also be found on major e-commerce Web sites, which usually provide both key word search functions and category browsing functions [53] (e.g., www.amazon.com, shopping.yahoo.com, and ebay.com). Interestingly, the set of products that are presented on the resulting Web pages are often organized in different information formats across different Web sites or even within the same Web site. For example, both eBay and Yahoo always use the list information format, where there is only one product on each line (see Figures 1a and 1b); Netgrocer, rated among the top ten e-commerce Web sites by the Los Angeles Times [76], uses the matrix information format, where there is more than one product on each line (see Figure 1c), when consumers use the browsing function, and the list format when consumers conduct direct search (see Figure 1d). Hence, there does not appear to be a consensus on the appropriate choice of information format. Since the decision on how to organize product information is one that every e-commerce Web site faces, there is a need for research to determine whether information format makes a difference to consumers with different shopping tasks, and if so, which information format is better at supporting which type of shopping task, and how it will influence consumers' online shopping behavior.

In this paper, using the cognitive fit theory [79] as the theoretical framework, we propose a research model to explain how the fit between information formats and shopping tasks may influence consumers' online shopping behavior. The competition-for-attention theory [36] and the scanpath theory [54, 55] are also employed to support the theoretical analyses. Specifically, we investigate how the fit between two information formats (list versus matrix) and two shopping tasks (searching versus browsing) can influence consumers' information search time, recall of product information, cognitive effort, and attitude toward using the Web site. The contributions of this research are twofold. From a research perspective, it integrates theories from different domains to help us understand the effects of the Web interface on consumers' online shopping behavior. From a practical perspective, the findings will have implications for the designers of e-commerce Web sites on how to best present product information to support different shopping tasks. 


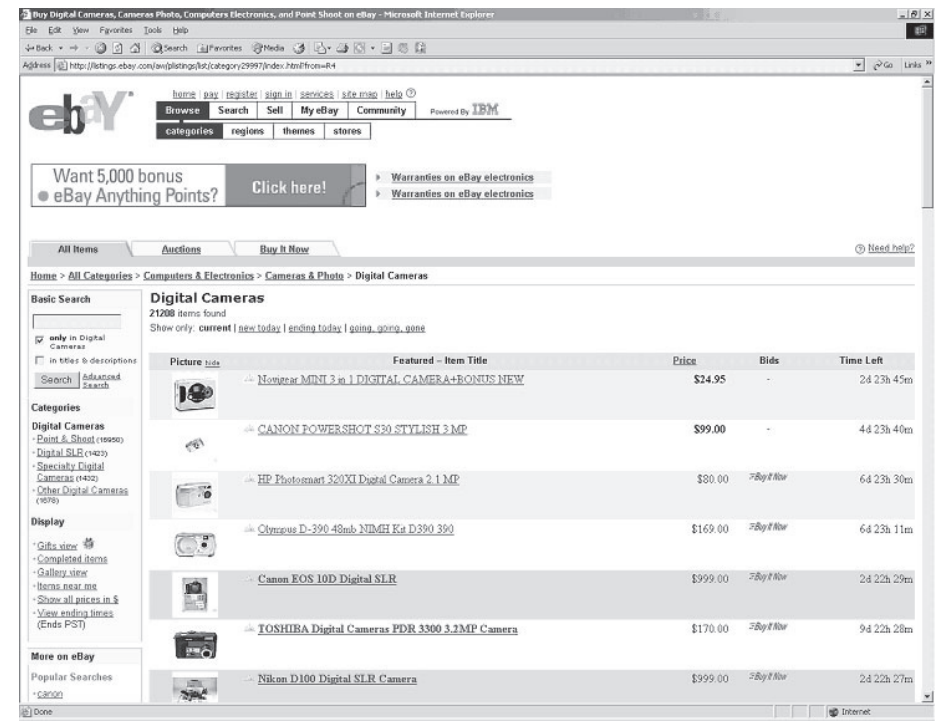

Figure 1a. eBay.com (November 2003)

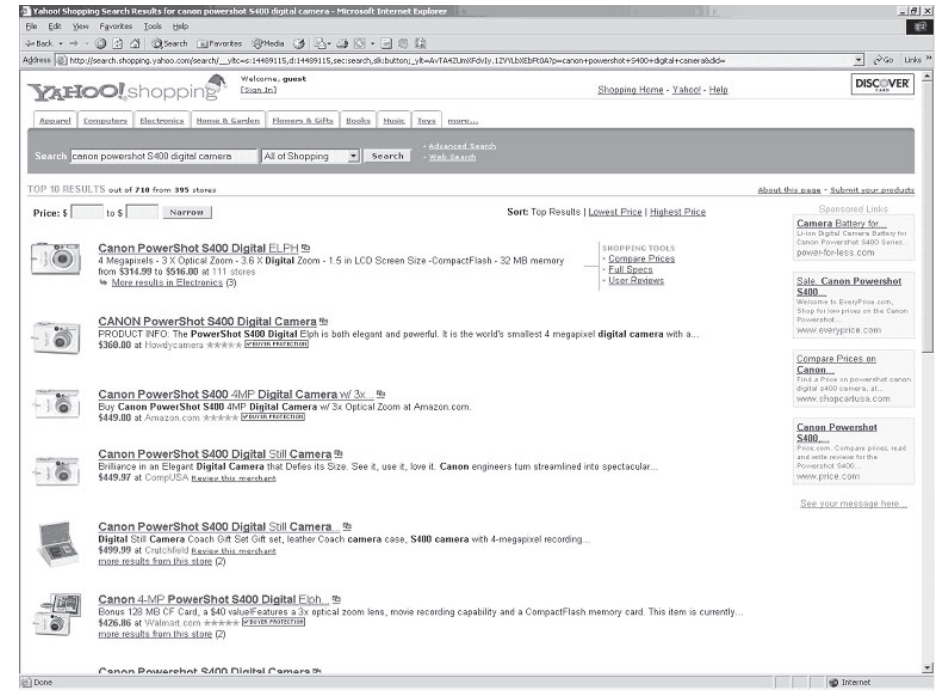

Figure 1b. Shopping. Yahoo.com (November 2003)

\section{Theoretical Background}

\section{Cognitive Fit Theory}

THE COGNITIVE FIT THEORY WAS DEVELOPED to help up understand how the fit between the presentation format and the decision-making task can influence individuals' problem solving performance [79]. It basically argues that the performance of 


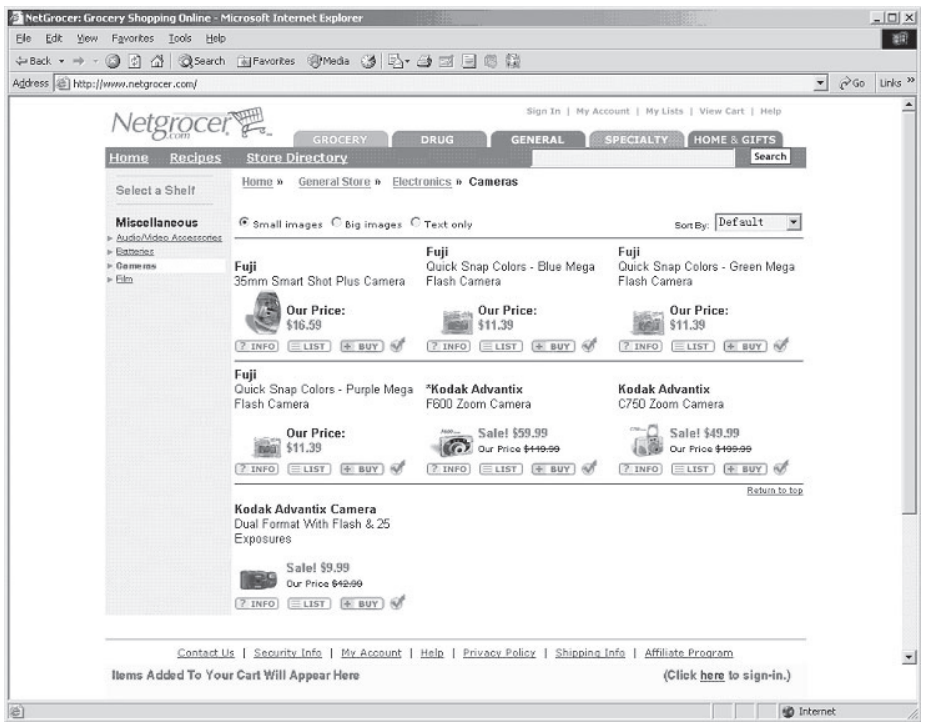

Figure 1c. Netgrocer.com-Browsing (November 2003)

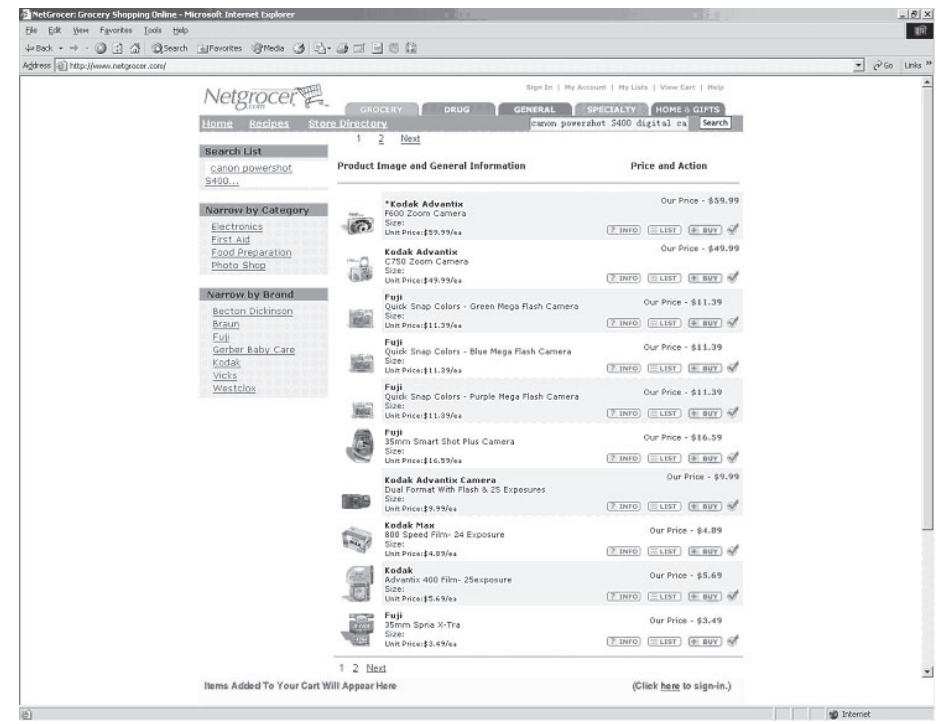

Figure 1d. Netgrocer.com-Searching (November 2003)

problem solving depends on both the problem representation (which we will refer to as information format in this paper) and the nature of the task. Different information formats, such as tables (symbolic representation) and graphics (spatial representation), emphasize different types of information and problem-solving processes. Similarly, different problem-solving tasks, such as trend detection (spatial task) and data value retrieval (symbolic task), also emphasize different types of information and 
problem-solving processes. The cognitive fit theory suggests that when both the information format and the task emphasize the same types of information and processes, a cognitive fit will occur, which produces a consistent mental representation for problem solving, and subsequently leads to faster and more accurate performance in decision-making. However, when there is a mismatch between the information format and the task, cognitive fit will not take place. Problem solvers will then need to transform some of the mental representation, inducing additional effort and resulting in relatively lower performance than when there is a cognitive fit.

The theory of cognitive fit has been empirically validated in a variety of problem domains, such as programming [70] and object-oriented modeling [1], and other data representation variations, such as multiattribute data [77], multimedia [34], and maps $[17,48,71]$. Moreover, the cognitive fit theory has been extended to include other variables such as problem-solving skills [80] and problem-solving tools [1, 70]. Cognitive fit will occur when the problem-solving elements (i.e., tasks, representations, skills, and tools) achieve consistent mental representation or when there is representation congruence of external information and the internal representation of the user [14]. These studies collectively suggest that cognitive fit, as a broad concept that subsumes the elements of the problem-solving process, may provide a useful theoretical framework for understanding the relationship between information formats on Web sites and consumers' online shopping tasks.

\section{Shopping Tasks: Searching Versus Browsing}

Consumers shop online with different intentions. Whereas some consumers have only a general idea of what they are looking for (e.g., I want to check out the latest contemporary music albums), others have more specific aims (e.g., I want to find the album "A New Day Has Come" by Celine Dion). Prior literature on e-commerce has identified two major types of shopping tasks that consumers conduct online: searching tasks and browsing tasks [13, 58, 72, 75]. Hoffman and Novak [31] related these two tasks with the goals that consumers have in mind and proposed that consumers engage in either goal-directed (search) or experiential (browse) behavior. Goal-directed behavior is characterized by extrinsic motivation, utilitarian benefits, and directed search, whereas experiential behavior is characterized by intrinsic motivation, hedonic benefits, and nondirected search.

While searching and browsing are deemed to be distinct activities on the Web, researchers also recognized that they represent two ends of a continuum rather than a strict dichotomy $[13,51]$. Hence, in this study, we differentiate between searching tasks and browsing tasks by the degree to which consumers are specific about their shopping objectives. Prior research suggested that consumers will act differently when they have different tasks in mind, and accordingly, different information technologies, such as navigation aids, should be provided [49, 72]. Therefore, this study incorporates both searching and browsing tasks in investigating the effect of information format on consumers' online shopping behavior. 


\section{Information Format: List Versus Matrix}

Information format is defined as the presentation and organization of information about the available alternatives and their attributes [16]. On e-commerce Web sites, there are two popular formats to organize multiple product information on a Web page. The first format is to display only one product in each row, which we call the list format. The second format is to display more than one product in each row, which we refer to as the matrix format. Given the same product information (e.g., brand names, product images, prices, etc.), Web site designers can choose to organize this information in either the list or the matrix format. To analyze the difference between the two, we introduce the competition-for-attention theory [36] from the marketing literature in the following subsection. Moreover, the scanpath theory from vision research will be incorporated to analyze the fit between the information formats and shopping tasks.

\section{Competition-for-Attention Theory}

The competition-for-attention theory [36] can be used to provide us with an understanding of how the matrix and list formats differ with regard to competition for attention. Human attention can be conceived of as a limited processing capacity that can be allocated in varying amounts to different locations in the visual field [59, 68]. Allocation of attention depends on both the salience of the object in the visual field and its distance from the area of focal attention. It is widely accepted that the physical salience of objects, such as size and color, is an important determinant of attention in printed media [33, 63]. For example, the bigger the size of an advertisement, the greater the possibility that it will receive consumers' attention. Research in human vision and perception also suggests that the distance of an object from the area of focal attention can determine the amount of attention it receives [4]. The further away from this area an object is, the less chance it has to capture the attention. Therefore, for an object to maintain a similar level of attention when it is removed from the fovea (i.e., area of eye receiving information from the current area of focus), its size has to be increased.

Based on the relationships between the attention and both the size of an object and its distance from the focal area, the competition-for-attention theory views multiple objects on a screen as potential candidates that are competing for attention. When an object is under focal attention, the other objects on the screen will constantly exert competition for attention. The amount of competition for attention that the focal object receives from each competing object can be calculated as the square root of the size of the competing object divided by the distance between them [36]. By summing the total amount of competition for attention from the competing objects, the relative

potential of each object on the screen to receive attention can be ascertained. A series of experiments conducted by Janiszewski [36] confirmed that competition for attention will affect not only the duration of eye fixation that an object receives but also 
the efficiency of information processing, and even the sales of catalog products. Similarly, by employing the competition-for-attention theory, we can understand the effects of different information formats on consumers' online shopping behavior.

Following Janiszewski's [36] formula, we calculated the total level of competition for attention for both the list and the matrix information formats (see Appendix A). An interesting finding is that, given a fixed screen size and uniform product information content, arranging products in either the list or the matrix format will result in significantly different levels of competition for attention. Using six brands per screen as an example, the total competition for attention in the list format (52.2) is more than twice that in the matrix format (23.4). ${ }^{2}$ Hence, the list format represents a high-competition-for-attention environment, whereas the matrix format represents a low-competition-for-attention environment. In summary, the competition-for-attention theory suggests that given the same screen size, different information formats can generate different levels of competition for attention.

\section{Local and Global Scanpaths}

The scanpath theory was proposed by Noton and Stark $[54,55]$ to model the patterns of eye movements while viewing and recognizing objects. Eye movements are composed of saccades and fixations. Saccades are the quick jumps of the eye from one location to another, during which vision is essentially suppressed; and fixations are the pauses between saccades, during which the eye is relatively immobile [62]. Scanpaths refer to the sequences of fixations. The theory proposes that subjects will follow certain scanpaths when viewing and recognizing the same stimulus. Two types of scanpaths have been identified and empirically validated [26, 27]. The first type is called local scanpaths, where fixations follow each other in an immediate physical succession. In local scanpaths, eye movements are regulated by momentary fixations based on peripheral information in a bottom-up mode. Peripheral information in the visual field will therefore determine the fixations and local scanpaths. The second type is called global scanpaths, which reflect distribution of fixations over a longer time frame irrespective of the immediate physical succession. In global scanpaths, fixations are usually distributed over the visual field and located more loosely with each other. In contrast to local scanpaths, global scanpaths are directed by some topdown processes such as search plans or cognitive strategies.

When consumers are engaged in browsing tasks, they usually have a less precise goal $[64,75]$. In fact, browsing behavior has also been considered as experiential [31], because the browsing activities are typically affected by the process itself rather than by well-articulated goals or outcomes [8]. Therefore, online consumers with browsing tasks are more likely to be influenced by the shopping environment, especially the design of the Web site. In such cases, the eye movements are likely to be influenced by peripheral information in a bottom-up manner, which emphasizes local scanpaths. Alternatively, when consumers are engaged in searching tasks, they are typically directed by some inner plans to make an active search $[24,46]$. In such

cases, the in-store searching behavior is very focused and targeted toward a specific 
and immediate purchase [50,65]. Consumers are less likely to be influenced by the shopping environment, but rather follow some internal search plan based on their knowledge of the Web site. Therefore, the fixations will be regulated by some topdown processes, which fit the characteristic of global scanpaths.

Meanwhile, scanpaths are also influenced by the stimulus [26]. In a high-competition-for-attention environment (the list information format), no matter which object on the screen is receiving the focal attention, the eyes are constantly under strong attraction to shift attention to some nearby objects that exert strong competition for attention [36], emphasizing a local scanpath. On the other hand, the matrix information format is better at supporting global scanpaths. In a low-competition-for-attention environment, the eyes can move more freely over the information space without being unduly distracted by the surrounding objects [36]. Moreover, when the sizes of the objects on the screen are similar (which is typically the case on e-commerce Web sites), the competition for attention exerted by the surrounding objects in the matrix format will be at similar levels, and the eyes will be under little pressure to shift attention to any one of them. Therefore, the eye fixations are more likely to distribute over a longer time frame, which corresponds to a global scanpath.

\section{Summary}

Based on the prior discussion, the cognitive fit theory suggests that the information format should match the consumers' online shopping tasks to ensure better performance and more positive shopping experience. However, while the cognitive fit theory provides the overall framework to our research model, it cannot tell us which information format will fit best with which shopping task. In order to understand the processes involved, we turned to the competition-for-attention theory and the scanpath theory to fine-tune the model. Using these two theories to understand how human attention is affected by the different information formats and how eye movements tend to reflect different decision-making modes, our analysis suggests that the list format matches browsing tasks because they both emphasize local scanpaths, and the matrix format matches searching tasks because they both emphasize global scanpaths. ${ }^{3}$

\section{Research Model and Hypotheses}

THE RESEARCH MODEL IS PRESENTED in Figure 2. According to prior research in marketing and e-commerce, consumers shop online for both goal-oriented and experiential reasons [5,31]. Therefore, two types of measures can be included when studying consumers' online shopping behavior [69]. The first type is performance measures, including shopping efficiency (as reflected by the time used) and communicative effectiveness (as reflected by the product information that consumers can recall from the Web site). The second type is related to shopping experience, such as consumers' perceptions of cognitive effort in completing the shopping tasks and their attitude toward using the Web site. Based on the prior theoretical background, we propose 


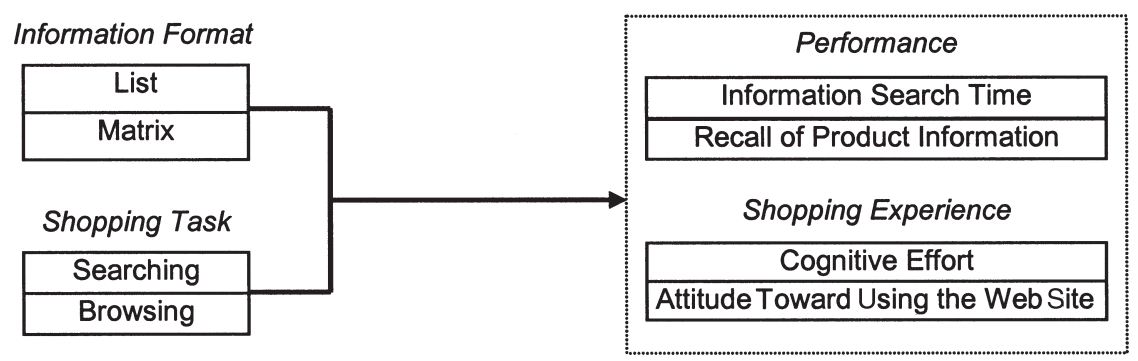

Figure 2. Research Model

that when there is a match between the information formats (list versus matrix) and the shopping tasks (searching versus browsing), more positive outcomes in terms of the two types of measures will result. We now discuss each of the dependent variables and the related hypotheses.

\section{Performance}

Time is often used as an indicator of performance in decision-making tasks involving different information formats (e.g., [6, 37]). Less time indicates more efficient decision-making and better interface design, which are desirable to both system designers and system users. For online shopping systems, the situation is more complicated. Whereas time saving is one of the major reasons that consumers purchase on the Internet [44], it may not be equally desirable to online retailers. On one hand, they want to design online shopping systems that facilitate consumers' information search. On the other hand, they want to retain the consumers as long as possible on their Web sites, exposing them to more product information. ${ }^{4}$ Balancing these dual goals of online retailers is a major challenge for Web site designers. In this study, we select time as a performance measure of information search efficiency, and define it as the time that consumers spend on searching or browsing for desired products on the Web site.

Recall is another dependent variable that is frequently adopted in both IS research (e.g., $[18,78])$ and marketing research (e.g., $[30,61])$ to indicate the effectiveness of communication by different information formats. Unlike the traditional IS, which have objective performance measures such as accuracy, an online shopping system often cannot be evaluated in terms of accuracy unless there is a specific search target to be found on the Web site. Hence, accuracy is relevant to the searching task but not the browsing task. As an online shopping system not only helps to complete transactions but also conveys information of other products to the consumers, how effective the system is in transmitting product information to the consumers becomes an important measure to online retailers [25]. Consumers' recall of product information on the Web pages can be used as an indication of the degree to which the Web site is successful in conveying product information to the consumers. A high level of product information recall is desirable to online retailers. Therefore, we select recall as 
another performance measure, and define it as the amount of product information (i.e., brand names and product images) that consumers can recall from the Web site. From the earlier analysis, we propose an interaction effect between the information format and the shopping task on performance measures. When there is a match between the two, consumers will perform better in their decision-making processes, because effort expended on adjusting any mismatched mental representation can be minimized. Specifically, we expect that the list format, which supports local scanpaths, matches the browsing task, and the matrix format, which supports global scanpaths, matches the searching task. As a result, not only will the consumers' information search time be shorter $(\mathrm{H1})$, but their recall of product information will be higher (H2).

H1: Information search time will be shorter when the information format matches the shopping task (i.e., the list information format matches the browsing task, and the matrix information format matches the searching task).

H2: Recall of product information will be higher when the information format matches the shopping task (i.e., the list information format matches the browsing task, and the matrix information format matches the searching task).

\section{Shopping Experience}

The consumers' perceptions of their shopping experience, including cognitive effort and attitude toward using the Web site, were also measured. Cognitive effort refers to the psychological costs of performing the task of obtaining and processing the relevant information in order to arrive at one's decision [60]. For e-commerce, effort reduction is a salient factor affecting consumers' intentions to shop online [38]. Conceivably, consumers would prefer to complete their shopping tasks with as little cognitive effort as possible (unless they are just surfing on the Internet). Therefore, we include cognitive effort as an indicator of a user-friendly interface design.

The consumers' attitude toward using the Web site for online shopping is another variable of interest. Attitude toward a behavior refers to a person's judgment that performing the behavior is favorable. Attitude is a reliable indicator of behavior intention, which subsequently affects actual behavior [2]. Online retailers would want consumers to have a positive attitude toward using their Web sites, because a positive attitude will eventually lead to the actual purchasing behavior. Therefore, we include attitude toward using the Web site as a dependent variable in this study.

We also propose an interaction effect between the information format and the shopping task on cognitive effort and attitude. The cognitive fit theory suggests that when there is a mismatch between the information format and the shopping task, the consumers will invest more effort in decision-making processes because they need to adjust their mental representation to accommodate the mismatch. Hence, we propose that cognitive effort will be lower when the information format matches the shopping task (H3). Similarly, a more positive attitude from the shopping experience will be formed if the consumers' shopping tasks are well supported by the information formats. Due to 
the matches between the list format and the browsing task and between the matrix format and the searching task, we expect that attitude toward using the Web site will be more positive when the list format is provided for the browsing task and the matrix format is provided for the searching task (H4).

H3: Cognitive effort will be lower when the information format matches the shopping task (i.e., the list information format matches the browsing task, and the matrix information format matches the searching task).

H4: Attitude towards using the Web site will be more positive when the information format matches the shopping task (i.e., the list information format matches the browsing task, and the matrix information format matches the searching task).

\section{Research Method}

WE EMPLOYED A $2 \times 2$ BETWEEN-SUBJECT FULL-FACTORIAL DESIGN. The two independent variables are shopping tasks (searching versus browsing) and information formats (list versus matrix).

\section{Subjects and Incentives}

A total of 118 business undergraduate students were recruited for the experiment. Participation in the study was voluntary. The subjects were paid HK\$100 (US\$1 = HK\$7.8) for their participation. Their average age was 20 years, and 70 percent were female. Four experiment sessions were conducted over two days with two sessions per day in a laboratory with 60 identical Pentium III personal computers connected to the Internet. The subjects were randomly assigned to each of the four experimental conditions (see Table 1). Aside from the monetary incentive for participation, the subjects were also given an opportunity to win one of the products they purchased during the experiment based on their recall performance. ${ }^{5}$

\section{The Experiment Product and Web Site}

Grocery products were chosen as the context of the experiment for three reasons. First, its growing trend and potential is recognized by e-commerce researchers [38, 57]. Second, grocery products are familiar to most people. Finally, similarity among the product categories favors the Latin square design [41] that we used to balance the order of shopping trips and brands presentation.

An online grocery shopping system, written in ASP and Java, was developed specifically for this study. It was installed on a Win2000 server in the same local area network as the personal computers in the laboratory to ensure a consistent high network speed for all subjects. All the subjects accessed the system using the same Internet browser software (i.e., Internet Explorer 5.5). 
Table 1. Subjects Assignment

\begin{tabular}{lcc}
\hline & \multicolumn{2}{c}{ Information format } \\
\cline { 2 - 3 } Shopping task & List & Matrix \\
\hline Searching & 29 & 32 \\
Browsing & 28 & 29 \\
\hline
\end{tabular}

Pretest

The marketing literature suggested that product class knowledge, brand name, and price could influence consumers' information search and shopping behavior [10, 19]. In order to control for these biases, a pretest was conducted to identify six product categories with similar levels of familiarity to our subjects, and to select six fake or unfamiliar brand names within each product category to be used in the experiment. First, we identified 15 grocery product categories that we believed were relatively familiar to our subjects, and came up with 15 fake or unfamiliar ${ }^{6}$ brand names within each product category. Next, we asked 29 subjects (who did not participate in the main experiment) from the same sample pool to rate their familiarity with each of the product categories, and indicate whether they had heard of any of the brand names. $t$-tests were then performed to identify product categories that had similar levels of familiarity to the subjects. For each product category, only the brand names that were claimed to be unknown to all the subjects were included in the main experiment. After the product categories and the brand names were selected, other attributes of each brand of product were created by referring to the Consumer Reports of the United States and a similar type of local magazine. Following the practice in marketing research, price was controlled at \pm 5 percent within each product category. All product information was kept constant in all the experimental conditions.

\section{Independent Variables}

Each subject took part in six shopping trips, and was required to buy one brand of product in each of the six product categories. For searching tasks, subjects were given a shopping list of six specific brands of products, one brand for each of the six product categories. Similar to marketing experiments that investigated consumers' shopping behavior, we provided a cover story to the subjects. For the searching task condition, the cover story was that people usually shop online for convenience and time saving. Therefore, supposing that they needed to buy the specific brands of products on the shopping list, they would want to complete their purchases quickly and accurately. For the browsing task condition, the subjects were allowed to choose any brand for each of the six product categories. The cover story was simply that, as online shopping was getting popular, they might want to try it out for themselves on the Web site. The subjects were told that there were no right or wrong answers and that their judgments should be based on their personal preferences. Detailed product 
information for each brand of the products, including brand name, price, product image, and other attributes, was available online. For both tasks, the subjects were only pretending to buy products from the experiment Web site, and no actual trading took place.

Two information formats, list and matrix, were developed for the Web site (see Figures $3 \mathrm{a}$ and $3 \mathrm{~b}$ ). In the list format, six brands were displayed on the screen for each of the six product categories. The brands were organized in a top-down manner, with only one brand in each row. In the matrix format, the brands were organized in blocks with three brands in each row. Product information, font size, image size, and color scheme were held constant in both information formats.

As the order of presentation on the screen of an IS might affect consumers' information search and decision-making processes [47, 78], we balanced the order of the product categories and the order of the brands within each product category with a Latin square design. The Latin square design has greater power than completely randomized designs [41]. However, it has strict requirements on the number of levels for each variable (i.e., $4 \times 4,5 \times 5,6 \times 6$, etc.). Moreover, Latin squares that are smaller than $5 \times 5$ are not practical because of the small number of degrees of freedom, whereas Latin squares larger than $8 \times 8$ are very complex and seldom used [41]. Therefore, we decided to use a $6 \times 6$ Latin square design with six product categories and six brands of products within each category. Similarly, we balanced the order of the six shopping trips within the same Latin square design.

The choice of six shopping trips was also appropriate, as too many shopping trips may cause fatigue among the subjects. Having six brands of products within each product category may seem limited, especially in the browsing condition. However, due to the restricted screen size, only a limited number of products can be displayed on the computer screen at any one time. Therefore, online consumers need to either scroll down a long Web page or click the "Next Page" button when such a function is provided on the Web site. In either case, consumers have only a fixed number of products to examine at any one time on the computer screen.

In searching tasks, it would be ideal to return only one product that matches with consumers' expectations when they know precisely what they are searching for on a Web site. However, more often than not, the search result will display more than one item due to various limitations: (1) inability of consumers to remember the exact product information (e.g., they may only remember the product name, Canon Powershot, but not the model number, S400); (2) the inconvenience of typing in the full name of a product; (3) the design of the search engine (i.e., some search engines will return all the results that contain part of the search criteria rather than the full criteria (for example, searching for "Canon Powershot S400 digital camera" on netgrocer.com will return all the digital cameras it carries even though none of them is from Canon; designers of Web sites may have incentives to do this, so as to promote other products); and (4) inefficiency of the search algorithm (e.g., searching for the "A New Day Has Come" album by Celine Dion on Amazon.com will return 13 results; searching for ThinkPad T23 on IBM.com will return 39,445 results!). Due to these limitations, more than one item will normally be returned, which requires further inspection by the con- 


\begin{tabular}{|lll|}
\hline Sensation Generation Facial Tissues & HKS 9.90 \\
\hline Sani-Hanks Facial Tissues & HKS 9.25 \\
\hline Sorbent Facial Tissues & HKS 9.99 \\
\hline Sarth Wise Facial Tissues & HKS 9.05 \\
\hline & Sunpass Facial Tissues & \\
\hline & Aspen F acial Tissues & HKS 9.10 \\
\hline
\end{tabular}

Figure 3a. Screen Capture of List Format

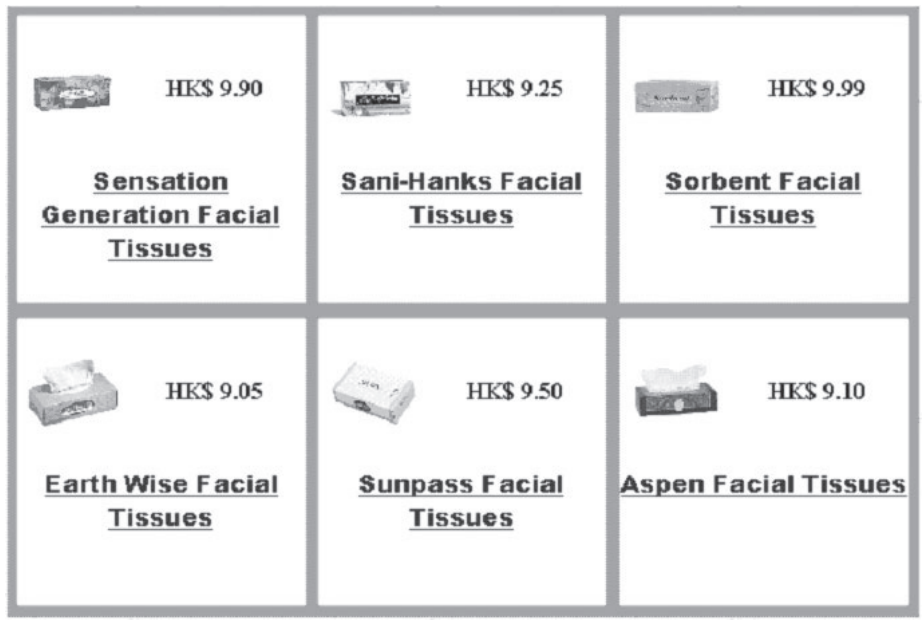

Figure 3b. Screen Capture of Matrix Format

sumers. As a result, we believe that the experimental design of six product categories and six brands of products within each category is appropriate for the experiment.

\section{Dependent Variables}

Information search time was measured in seconds by the average viewing time of the brands across the six product categories and was calculated from the users' computer $\log$ files. Recall of product information was assessed by two measures: recall of brand names and recall of images. ${ }^{7}$ The subjects were presented with 12 brand names (6 valid brands and 6 invalid brands) ${ }^{8}$ for each product category (i.e., distilled water, boxed chocolate, toothpaste, cookies, facial tissues, and orange juice), and were asked 
to identify the brand names that they had previously seen during their shopping trips. The score for recall of brand names was calculated by counting the number of correct identifications in each product category and then taking the average. Recall of images was measured in a similar way.

The perceptions of shopping experience were measured with a postsession questionnaire (see Appendix B). We assessed cognitive effort with two measures that were specially developed for the e-commerce domain and rephrased them to suit the current context. The first measure was cognitive decision effort with six items [60]. The second measure was cognitive convenience with two items from Kim and Yoo's [40] scale. 9 Ten-point Likert scales with anchors ranging from "strongly disagree" to "strongly agree" were used for all the items. Following the guidelines by Ajzen and Fishbein [2], attitude toward using the Web site was measured by two items with paired anchors of dislike/like and pleasant/unpleasant, respectively. An exploratory factor analysis of the multiple-item constructs suggested that one item from cognitive decision effort should be dropped, as it loaded higher on another construct. An examination of the dropped item found that it was semantically different from the remaining items. The revised constructs demonstrated adequate reliability and construct validity. Cronbach's alpha was 0.85 for cognitive decision effort, 0.72 for cognitive convenience, and 0.71 for attitude. Factor loadings on their intended constructs were all above 0.50 , with most of them above 0.70 and no cross-loadings higher than 0.30 . The scores on the items of each variable were aggregated for further analyses.

\section{Experimental Procedure}

An online shopping experiment could be affected by the characteristics of the subjects (e.g., prior online shopping experience) and stimulus (e.g., prices of products). Multiple methods were used to control for the effects of possible confounding variables and improve the internal validity of this study. The individual differences, including personality, cognitive style, and personal computer and Web experience, were controlled for by randomly assigning the subjects to the experimental conditions.

At the start of each experiment session, the subjects were told that all the instructions were provided online and that they should read the instructions carefully and complete the experiment independently. The subjects first entered their demographic information online. Next, a cover story was provided that an international company was intending to market its products online and had developed a Web site. Then, a trial shopping trip of a product category other than the six in the main experiment was provided to familiarize subjects with the Web site and the shopping process. After that, a description of the shopping task (searching or browsing) was given. The subjects then conducted a total of six shopping trips. In each shopping trip, the subjects were presented with six brands of a particular product category in either list or matrix format. They could click on a brand to retrieve detailed product description. A log file was generated to store the subjects' clickstream data. At the end of the shopping trips, the subjects completed a postsession questionnaire regarding their shopping experience. The questionnaire also serves as a filter task for the subsequent recall task. This 
was followed by the tasks to recall brand names and images. Finally, the subjects were debriefed. All the experiment sessions were administered by the same experimenter following a standard protocol.

\section{Results}

\section{Manipulation and Control Checks}

AMONG THE 61 SUBJECTS INVOLVED in searching tasks, 58 purchased the correct brands on all 6 shopping trips, with the remaining 3 making only 1 error, indicating they were concentrating on the experimental task. For browsing tasks, as the subjects were asked to freely choose one brand within each product category, there was no criterion for right or wrong answers. Moreover, the average number of clicks per shopping trip was significantly higher $(F(1,116)=400.234, p=0.000)$ in browsing tasks $($ mean $=7.547)$ than in searching tasks $($ mean $=1.098)$, confirming the successful manipulation of the shopping tasks.

We performed control checks on gender and subjects' experience with personal computers, the Internet, and online shopping. A multivariate analysis of variance (MANOVA) test suggested that the random assignment of the subjects to the four experimental conditions was successful. ${ }^{10}$ As there were more female than male subjects in the experiment, we compared the dependent variables for the two groups using $t$-tests. There were no significant differences between females and males in their information search time $(t=-1.474, p=0.143)$, recall of brand names $(t=-0.269$, $p=0.789)$, recall of images $(t=1.770, p=0.079)$, cognitive decision effort $(t=0.778$, $p=0.438)$, cognitive convenience $(t=-1.237, p=0.218)$, and attitude toward using the Web site $(t=-1.454, p=0.149)$. Statistical tests were also performed to see if there were any systematic biases on the dependent variables due to subjects' experience with personal computers, the Internet, and online shopping. There were no significant correlations between these control variables and the dependent variables. Hence, none of the control variables have an effect on the dependent variables under investigation.

\section{Hypotheses Testing}

The means and standard deviations of the dependent variables are presented in Table 2. A Levene's test showed that the variance of information search time was not homogeneous across treatment groups $(F(3,114)=7.116, p=0.000)$. Hence, a reciprocal transformation was applied to information search time before performing further analyses. A MANOVA test showed a significant interaction effect between the information format and the shopping task (Pillai's trace $=0.133$; Wilks's lambda $=0.867$; Hotelling's trace $=0.153$; Roy's largest root $=0.153 ; F(6,109)=2.788, p=0.015) .{ }^{11}$ Box's $M$ statistic, testing for the equality of the variance/covariance matrices of the dependent variables across the groups, was significant at 0.002 , suggesting the data was heteroscedastic. However, heteroscedastic data has a minimal effect on the results 
Table 2. Descriptive Statistics

\begin{tabular}{llrr}
\hline & & \multicolumn{2}{c}{$\begin{array}{c}\text { Information format } \\
\text { mean (std. dev.) }\end{array}$} \\
Dependent variables & $\begin{array}{c}\text { Shopping } \\
\text { task }\end{array}$ & \multicolumn{1}{c}{ List } & Matrix \\
\hline Information search time & Searching & $5.39(2.13)$ & $4.83(2.04)$ \\
& Browsing & $18.36(3.60)$ & $20.35(3.82)$ \\
Recall of brand names & Searching & $1.48(0.89)$ & $1.88(1.08)$ \\
Recall of images & Browsing & $2.50(0.97)$ & $1.93(1.05)$ \\
& Searching & $1.40(1.11)$ & $1.82(1.21)$ \\
Cognitive decision effort & Browsing & $3.91(1.14)$ & $3.32(1.55)$ \\
Cognitive convenience & Searching & $2.80(1.21)$ & $3.19(1.16)$ \\
& Browsing & $4.40(1.50)$ & $4.69(1.38)$ \\
Attitude toward using the & Searching & $7.19(1.35)$ & $7.41(1.17)$ \\
Web site & Browsing & $6.41(2.10)$ & $6.09(1.70)$ \\
\hline
\end{tabular}

of the MANOVA test when the groups are of approximately equal size - that is, if the largest group size divided by the smallest group size is less than 1.5 [28]. In our study, the largest group size was 32 and the smallest group size was 28 , giving a ratio of 1.14. Therefore, we could proceed to analyze the results for individual dependent variables. Table 3 summarizes the hypotheses testing results.

For information search time, the interaction effect $(F(1,114)=4.904, p=0.029)$ was significant, supporting H1. Subjects who were given matching information format for their assigned shopping task spent less time completing the task than subjects who received mismatching information format. Also, the direction of the interaction effect supports our hypotheses that the list format matches the browsing task and the matrix format matches the searching task (i.e., subjects using the list format took a longer time than subjects using the matrix format in searching tasks, while the opposite was true for browsing tasks). Figure 4a displays the mean levels of information search time in the four experimental conditions.

For recall, the interaction effects for both recall of brand names $(F(1,114)=6.905$, $p=0.010)$ and recall of images $(F(1,114)=4.690, p=0.032)$ were significant. Hence, $\mathrm{H} 2$ was supported. Generally, subjects who were provided with matching information format and shopping task could recall more information of both brand names and product images than subjects who were given mismatching information format and shopping task. Specifically, for searching tasks, recall of both brand names and images was better in the matrix format than in the list format. And for browsing tasks, recall was better in the list format than in the matrix format. The mean levels of recall of brand names and images are depicted in Figures $4 \mathrm{~b}$ and $4 \mathrm{c}$.

To further understand the three significant interaction effects, we conducted simple main-effects analyses of the information format for each of the shopping tasks. ${ }^{12}$ For browsing tasks, the $t$-tests showed that the list information format was significantly 


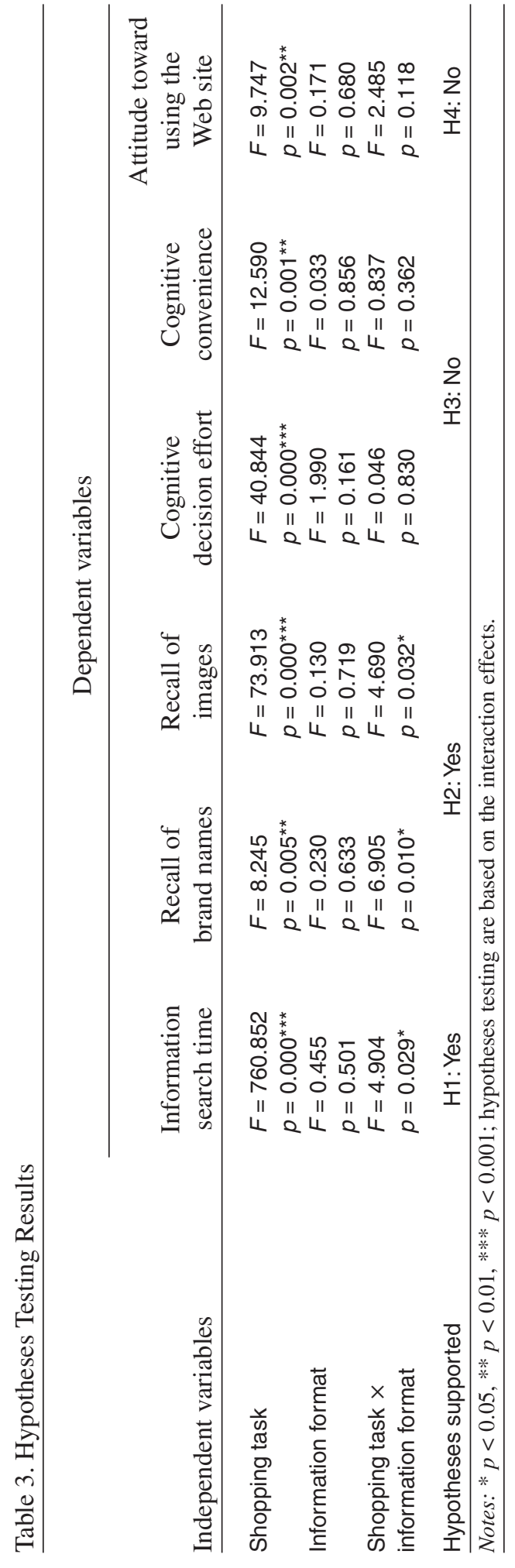




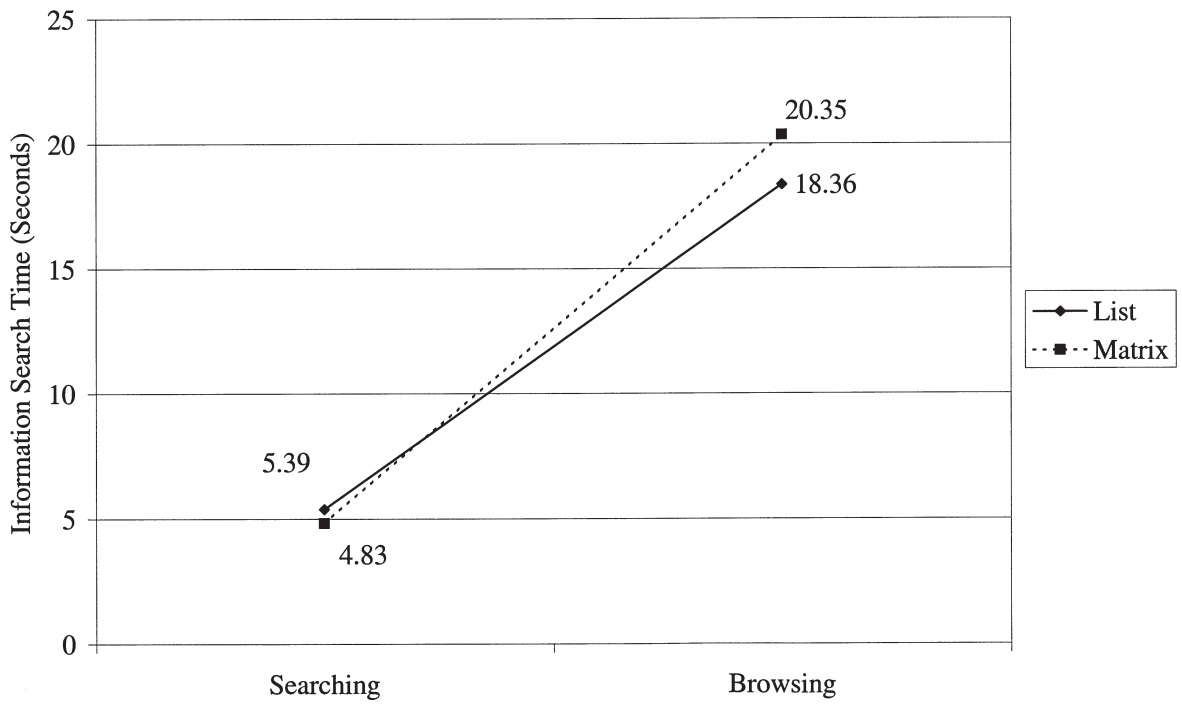

Figure 4a. Mean Levels of Information Search Time

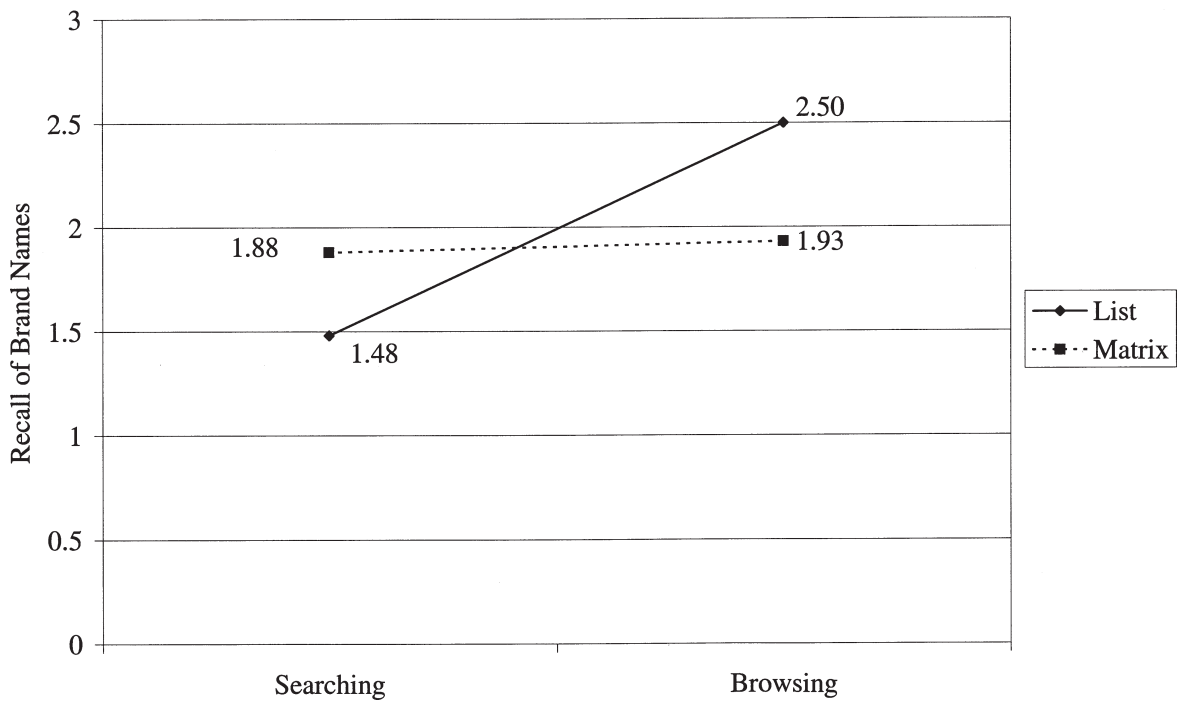

Figure $4 b$. Mean Levels of Recall of Brand Names

better than the matrix information format in terms of information search time $(t=-2.105, p=0.040)$, recall of brand names $(t=2.143, p=0.037)$, and recall of product images $(t=2.430, p=0.019)$. For searching tasks, the $t$-tests showed that the matrix information format significantly reduced information search time $(t=-2.155$, $p=0.036)$, and marginally increased recall of brand names $(t=1.877, p=0.066)$ and recall of product images $(t=1.766, p=0.083)$, as compared to the list information format. Overall, the simple main effects analyses provided further support for the hypotheses. 


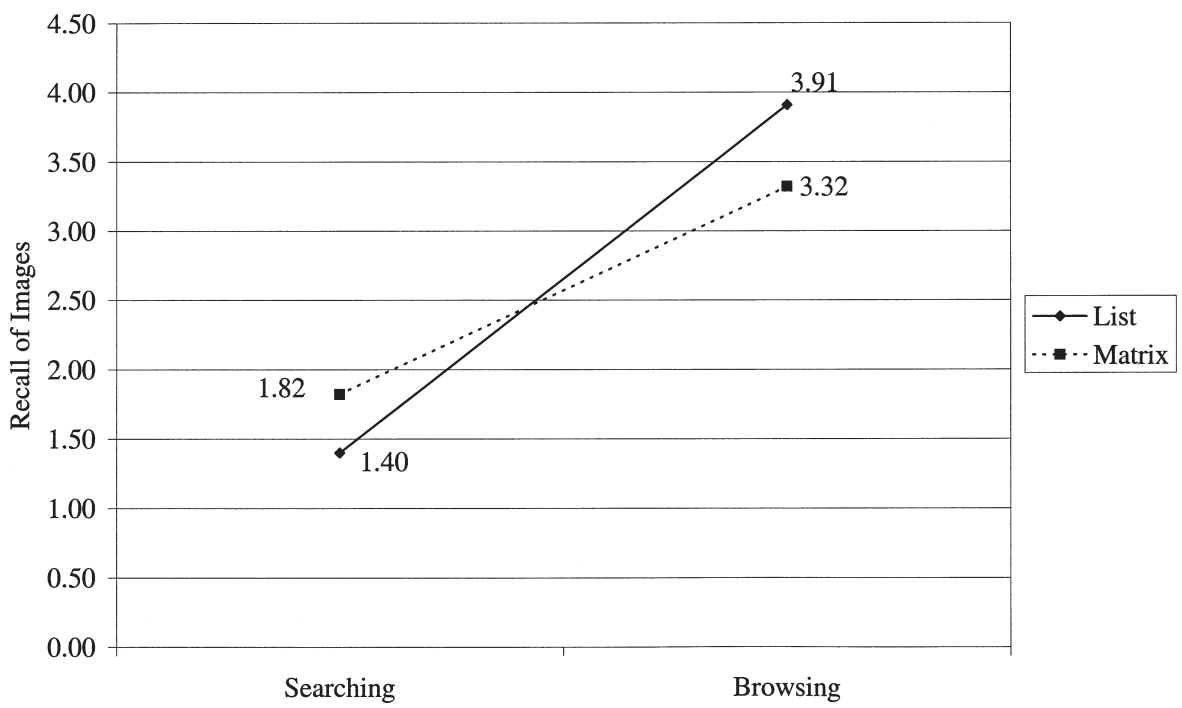

Figure 4c. Mean Levels of Recall of Images

For perceptions of shopping experience, the interaction effects were not significant at the 0.05 level, rejecting $\mathrm{H} 3$ and $\mathrm{H} 4$. However, the main effects of shopping task on cognitive effort $(F(1,114)=40.844, p=0.000$ for cognitive decision effort; $F(1,114)=$ $12.590, p=0.001$ for cognitive convenience) and attitude $(F(1,114)=9.747, p=0.002)$ were significant. The significant main effects of shopping task may not be that surprising, as searching tasks, by nature, require less cognitive effort to complete than browsing tasks. As a result, consumers conducting searching tasks will have a more positive attitude than consumers conducting browsing tasks.

\section{Discussion}

\section{Performance}

IN GENERAL, IT IS OBSERVED THAT A GOOD FIT between the information format and the shopping task will result in significant improvements in online shopping performance. When consumers are browsing for a particular product online, the high-competition-for-attention environment present in the list information format can significantly reduce their information search time and improve their recall of product information as compared to the low competition-for-attention environment present in the matrix information format. But when consumers are searching for potential products, the matrix information format will result in more efficient information search and more effective recall of product information than the list information format. These findings suggest that given the same information content, varying the information format is capable of influencing the consumers' online shopping behavior. Both online retailers and consumers will benefit from a Web site's interface design that applies these findings. 
Although consumers will want to complete their online shopping expeditiously, it is in the online retailers' interest to retain the consumers as long as possible on their Web sites so that more product information can be conveyed to them. The findings on information search time, and recall of brand names and images, have provided evidence that concerns over this dilemma are unwarranted, because it is actually possible to achieve both goals simultaneously. For both shopping tasks, when there is a match between the information formats and the shopping tasks (list format with browsing task; matrix format with searching task), the information search time can be reduced without sacrificing the effectiveness of product information transmission to the consumers. In both cases, the consumers can commit to memory more brand names and product images in a relatively short period of time when the information format supports the shopping task at hand. Collectively, the findings indicate that a good fit between the information format and the shopping task will result in more effective and efficient online shopping performance.

\section{Shopping Experience}

An interesting finding is that although there are significant interaction effects on the shopping performance measures, there is no such effect for the shopping experience measures. It seems that consumers are not conscious of the effects of the manipulation even though their shopping performance can be significantly affected. In a recent study on Web page design, Mandel and Johnson [45] manipulated the background pictures and colors of a Web page to influence consumers' product choices. Similar to the results in our study, they found inconsistency between consumers' product choices (which were affected by the design variables) and subjective perceptions. Specifically, although their subjects can recall the background pictures and colors, few admit that the visuals have affected their responses. As time is often used as an objective surrogate measure for cognitive effort (e.g., [37]), the findings concerning information search time in this study indicate that the information format does make a difference in cognitive effort for the shopping tasks. However, the lack of significant interaction effects on the perceptual measures suggests that consumers may not be aware of the cognitive effort involved, hence their attitudes are not changed accordingly.

The second possible explanation is that the time difference in completing a particular task (whether browsing or searching) using the different information formats is not large enough for subjects to sense the cognitive convenience or the appeal of the Web site design. On average, when the information format matches with the shopping task, the subjects save 12 percent of the time in the searching tasks and 11 percent of the time in the browsing tasks. Therefore, even though there is significant time saving, it may not be obvious to the subjects. Similar results have been reported in $\mathrm{Yu}$ and Roh's [82] study on the menu design in an information-seeking context. Although there was significant difference in information-seeking performance (i.e., the speed with which their subjects completed the shopping tasks), there was no significant difference in terms of their subjects' attitude toward the Web site. 
The third possible explanation is that the sample size of this study is not large enough to detect the differences in the perceptual measures of shopping experience. A power analysis was performed following Cohen's [15] guidelines. Following the common practice in social science research, a medium effect size was assumed. ${ }^{13}$ The effect size is an indication of the existence of a difference among treatment groups. For our sample size and a medium effect size, the power of each statistical test on the interaction effect was 0.77 . Therefore, the sample size of this study is adequate to confirm the insignificant interaction effects between the information format and the shopping task on consumers' perceptions of their shopping experience.

\section{Implications for Research}

In recent years, there has been an increased interest in studying the Web interface design. It is generally agreed by IS as well as marketing researchers that the Web interface design plays an important role in shaping consumers' online shopping behavior and attitude toward the Web site (e.g., [42, 56]). Our research contributes to this literature in five important areas.

First, although it is generally acknowledged that consumers go online for different purposes [9, 50, 64], there is little research into the design of the Web interface to support the different shopping tasks. Although some researchers have started to recognize the importance of adapting the view or the tools of the Web site to the task at hand [58, 73], most studies examine Web design features in a given context - that is, either searching (e.g., [82, 83]) or browsing (e.g., [11, 75]). It is not clear how the design features under investigation in these papers will affect consumers' online shopping behavior in other situations. Our study shows that to arrive at a more systemic understanding of a particular design feature, it is imperative to study the design element in various shopping contexts.

Second, this study applies the cognitive fit theory to interface design in the e-commerce domain and provides evidence of the importance of task-representation fit in this new context. The cognitive fit theory is not restricted to the graphs-versus-tables domain and can be applied to any domain where there is sufficient information to permit analysis of the tasks and the information presentation formats [79]. Previously, the cognitive fit theory has been applied to the domains of decision support systems, geographical information systems, and programming. The e-commerce Web site, which serves as both a marketing tool for product information dissemination and a sales transaction system, is different from the traditional IS in many ways. For example, for most of the computer-assisted problem-solving tasks, there exist correct solutions, whereas for online shopping tasks, it is more a matter of personal preferences than of right or wrong answers. An e-commerce Web site not only provides an environment to facilitate consumers' decision-making but also communicates product information and creates an enjoyable experience. Our findings support the use of the cognitive fit theory in understanding consumers' online shopping performance and extend it to include the visual fit between the shopping task and the information format. Hence, this study adds to the task-representation literature by testing the cognitive fit theory in the e-commerce 
domain and highlighting the importance of taking into account the shopping tasks in examining Web design features.

Third, prior research focuses on the design of Web pages in the earlier stages of the online shopping process-for example, the menu [82], the navigation structure [58, $83]$, and the search engine [20, 23]. Less research effort has been found in the design of Web pages for the later stages of the online shopping process - that is, the Web pages that contain the searching or browsing results. As these pages are closer to the final purchase decision, they have great potential in influencing consumers' online shopping behavior. The findings of our study confirm that the design of Web pages for the later stages of the online shopping process can influence consumers' information search time as well as their degree of information recall.

Fourth, an e-commerce Web site bears the characteristics of a marketing channel, which suggests the possibility of applying existing marketing theories in investigating consumers' online shopping behavior. Since reading is significantly different in the printed media versus the electronic media [52, 81], research findings on the traditional printed media need to be applied with care to the electronic media. In this study, we have used the competition-for-attention theory, originating from the marketing literature, to understand the effect of two information formats on consumers' shopping performance in the e-commerce domain. The results confirm that attention is an important resource in the online environment. Multiple objects on the screen will constantly compete for limited attention, and such competition can greatly influence consumers' information search time as well as information recall performance. Note that the findings from marketing research are not always transferable to the new electronic media. For example, Hoque and Lohse [32] found that although the size of yellow pages' advertisements was traditionally believed to be an important determinant of attention, such an effect was not evident in their electronic versions due to the limitation of screen size. Hence, it is important to determine the applicability of these marketing theories in new domains.

The fifth contribution of this study is the introduction of vision research theories to the e-commerce domain. The traditional vision studies used experimental conditions that were very different from those in the online settings. The visual stimuli in the traditional vision research are usually quite simple (e.g., drawing of polygons), whereas the online setting is much more complex. Also, the experimental tasks in the traditional vision research are composed of relatively simple activities, such as viewing and recognition, whereas the online shopping tasks involve more complications, such as consumers' familiarity with the Web sites, their previous knowledge of the product category, and personal preferences. Despite these differences, our findings suggest that knowledge from vision research can still be valuable in understanding how the Web interface affects consumers' online shopping behavior.

\section{Implications for Practice}

Prior research has found that the design of the product listing pages accounts for 61 percent of the variance in monthly sales and explains over 7 percent of the variation 
in store traffic [43]. The current study provides practical implications for online retailers and Web site designers on how to design these product listing pages. First, both list and matrix information formats should be provided when organizing product information on Web interfaces. Depending on the specific shopping tasks they have in mind, online consumers can generally be categorized into two types: searchers or browsers. Web site designers should cater to both types of consumers ${ }^{14}$ by providing both list and matrix information formats in the Web interfaces to help them conduct more efficient information search and more effective product information recall.

Second, the findings of this study can provide guidance as to which type of information formats in the Web interface will suit particular shopping tasks of online consumers. Web site designers should match the information format of the product listing pages to the shopping task of online consumers. When consumers have specific objectives about what to look for online, Web site designers can arrange product information in a matrix format to assist searching. On the other hand, when consumers have only general objectives about what to look for online, it is better to organize the product information in a list format to facilitate efficient browsing. The value of this implication rests in the fact that when the information format provided matches the shopping task, online consumers can both save time in conducting their shopping and absorb more product information simultaneously.

Nevertheless, a challenge remains as to how to learn of a consumer's online shopping task. One way of doing this is by analyzing the profile of online consumers and their log files. Based on both input information (such as the key word search terms) and traced information (such as order history and clickstream log files), online retailers can assess how specific a consumer's shopping goal is on a particular shopping trip. For example, if a consumer has typed in a general key word search term, such as "digital camera," it can be safely assumed that he or she is browsing for digital cameras, so the list format can be provided. If the search term is more specific, such as "Canon Powershot S400 digital camera," it is more likely that the consumer is searching for a particular model of digital camera, so the matrix format can be provided. Given the rapid development of data warehouse and data mining technology, and the increasing bandwidth of the Internet, online retailers will become better at predicting consumers' online shopping tasks.

Finally, as our findings are derived from a controlled experimental setting, one may wonder to what extent these findings are generalizable to more realistic e-commerce settings. In a typical online shopping scenario, a consumer may face a large number of Web sites selling the same kind of product (instead of one Web site in the experiment), and each of these Web sites may carry a large number of brands of each product (instead of six brands for each product). The popular use of search engines may also affect the way in which online consumers search for a product. However, one thing remains unchanged: at any given time, the number of products that a consumer can examine is limited by the screen size. Therefore, the total performance difference that the information format makes on one screen will be amplified through longer Web pages, multiple Web pages, and multiple Web sites. For example, assuming that 
a consumer is browsing a Web site for a product, and there are 30 brands of that product on the Web site, where only 6 of them can be displayed at a time on the computer screen, then the consumer needs to scroll down five times to see all the products. As a result, there will be a 5 times difference in browsing time when this consumer is provided with the list information format as compared to the matrix information format. Further, considering that the consumer may need to scroll up and down many times to compare brand information, the time difference will multiply. If this consumer visited more than one Web site, then the time difference would be even more significant. In the case of search engines, typically a very large number of results will be returned and displayed over many pages. Following from the above discussion, the difference in searching time will be many times more than that observed in the controlled experimental setting.

\section{Limitations}

There are some limitations to this study. First, the level of competition for attention and the subjects' scanpaths were not measured directly. Competition for attention is a theoretical concept that cannot be measured explicitly, and instead, a rough measure is computed using the Janiszewski [36] formula. Although Janiszewski's measure is not an exact measure of attention, it suffices for our purpose, as we are primarily interested in the relative degree of competition for attention between the information formats. In the case of scanpaths, they could potentially be recorded with an eyetracking machine. However, eye-tracking devices normally require the installation of a headset on the subjects, which can distort their natural online shopping behavior and subsequently affect their observed shopping performance and experience.

Second, cognitive convenience and attitude toward using the Web site were each measured with only two items. As the constructs demonstrated adequate reliability and construct validity, we believe that this limitation will not have a serious effect on the research findings. Nevertheless, future research could use more items to measure these constructs to enhance their reliability further.

Third, the design of the experiment Web site is relatively simple compared to commercial Web sites, and the number of products under each product category is relatively small. The simplified Web site design helps to increase the internal validity of the experiment by controlling for the effects of exogenous interface variables that may interact with the independent variables in this study. The number of products displayed was fixed at six to meet the requirements of the Latin square design. If more products were included, the subjects would need to either scroll down a long Web page or click the "Next Page" button if such a function was provided. In either case, only a fixed number of products can be viewed on the screen at a time. Therefore, we believe that the experiment Web site design captures the essentials of a typical online shopping environment while preserving internal validity. If a more realistic e-commerce setting is preferred, then a field study will be needed. Researchers will have to be careful when interpreting the results of such field studies, as the dependent 
variables are jointly affected by a number of factors (e.g., knowledge of particular products, familiarity with particular Web sites, brand preferences, price sensitivity, downloading speed, etc.) other than the Web site design.

\section{Conclusions}

THIS STUDY HAS EXAMINED THE ROLE of information format in influencing consumers' online shopping behavior. Utilizing the cognitive fit theory as the theoretical framework, our analysis suggests that consumers' online shopping performance is influenced by both the information format utilized and the shopping tasks. By matching the information formats of a Web interface with consumers' online shopping tasks, the time that consumers spend searching for desired products can be shortened while their recall of product information on the Web site can be improved. Furthermore, consumers may not consciously be aware of these effects, suggesting that online retailers can influence consumers in a desired way by manipulating the information format to suit consumers' online shopping tasks.

Future research can build on the findings of this study in other settings using different intervening variables. For example, they can examine whether the findings still hold when familiar brand names are used, or when there are greater price variations. Moreover, the effects of other interface characteristics, such as size of images or text and use of animation, can be examined. The predictive power of the cognitive fit theory, the competition-for-attention theory, and vision research in investigating the effects of the Web interface on consumers' online shopping behavior can also be further explored. Continuing research will contribute to a better understanding of the role of the information format in improving decision-making performance in cyberspace.

Acknowledgments: The authors thank the three anonymous reviewers for their constructive comments on early versions of the paper. This project was partially funded by the RGC grant HKUST6194 and the Research Center for Electronic Commerce at the Hong Kong University of Science and Technology.

\section{NOTES}

1. Note that the browsing task that we are referring to in this paper is different from "surfing," which is browsing as its own end (i.e., without any particular purpose).

2. Note that the relative level of competition for attention in the list and matrix information format remains similar for other numbers of brands (e.g., in a 9-brand condition, the competition for attention is 121.14 in the list format and 50.0 in the matrix format, respectively).

3. Although the competition-for-attention theory and the scanpath theory provided us with plausible explanations for the fit between the information format and the shopping task, they do not rule out the possibility of other theories that may provide alternative explanations for these predictions.

4. Even though longer exposure time does not guarantee that consumers are retained on the Web site (e.g., consumers may not be concentrating on the information), research has shown 
that mere exposure to brand name or product information can have a positive effect on consumers' attitude toward the product [35, 67].

5. Subjects were not informed of this opportunity until they came to the recall task. Hence, their shopping behavior would not be affected by it.

6. Unfamiliar brand names were chosen from products in a foreign country.

7. The recall tasks were conducted at the end of the experiment after completion of a questionnaire on perceptions of shopping experience.

8. The six invalid brands were also selected based on the pretest and, therefore, unfamiliar to the subjects.

9. The original scale has three items. However, one of the items is not relevant to the searching task and, hence, is not included in the current study.

10. Pillai's trace $=0.154, F=1.208, p=0.263$; Wilks's lambda $=0.853, F=1.197, p=0.272$; Hotelling's trace $=0.163, F=1.184, p=0.282$; Roy's largest root $=0.083, F=1.861, p=0.107$.

11. A significant main effect of shopping tasks $(F(6,109)=160.22, p=0.000)$ was also found but not discussed because, when the interaction effect is significant, the main effects should not be interpreted $[39,41]$. The main effect of information format $(F(6,109)=0.531$, $p=0.783$ ) was not significant.

12. We also performed simple main-effects analyses of the shopping task for each of the information formats, even though they were not the focus of this research, where the shopping task should be the moderator. The results showed that all the simple main effects of the shopping tasks were significant at 0.001 , except for the effect of shopping task on recall of brand names under the matrix information format.

13. We also estimated the effect size based on the observed sample means and within-cell standard deviations. The effect size of the interaction effect was 0.21 for information search time, 0.25 for recall of brand names, and 0.21 for recall of images. Therefore, it seemed appropriate to assume a medium effect size.

14. Even though searchers typically have fewer products to examine before making the purchase as compared to browsers, the issue of multiple-brand presentation is still relevant to both of them, as it is often difficult to retrieve the exact product that searchers are looking for (see the last paragraph of the "Independent Variables" section for a more detailed discussion).

\section{REFERENCES}

1. Agarwal, R.; Sinha, A.P.; and Tanniru, M. The role of prior experience and task characteristics in object-oriented modeling: An empirical study. International Journal of HumanComputer Studies, 45, 6 (1996), 639-667.

2. Ajzen, I., and Fishbein M. Understanding Attitudes and Predicting Social Behavior. Upper Saddle River, NJ: Prentice Hall, 1980.

3. Alba, J.; Lynch, J.; Weitz, B.; Janiszewski, C.; Lutz, R.; Sawyer, A.; and Wood, S. Interactive home shopping: Consumer, retailers, and manufacturer incentives to participate in electronic marketplaces. Journal of Marketing, 61, 3 (1997), 38-53.

4. Anstis, S.M. A chart demonstrating variations in acuity with retinal position. Vision Research, 14, 7 (1974), 589-592.

5. Babin, B.J.; Darden, W.R.; and Griffen, M. Work and/or fun: Measuring hedonic and utilitarian shopping value. Journal of Consumer Research, 20, 4 (1994), 644-656.

6. Benbasat, I., and Dexter, A.S. An experimental evaluation of graphical and color-enhanced information presentation. Management Science, 31, 11 (1985), 1348-1364.

7. Benbasat, I., and Dexter, A.S. An investigation of the effectiveness of color and graphical information presentation under varying time constraints. MIS Quarterly, 10, 1 (1986), 59-81.

8. Bloch, P.H.; Sherrell, D.L.; and Ridgway, N.M. Consumer search: An extended framework. Journal of Consumer Research, 13, 1 (1986), 119-126.

9. Breitenbach, C.S., and Van Doren, D.C. Value added marketing in the digital domain: Enhancing the utility of the Internet. Journal of Consumer Marketing, 15, 6 (1998), 558-575.

10. Brucks, M. The effects of product class knowledge on information search behavior. Journal of Consumer Research, 12, 1 (1985), 1-16. 
11. Bucklin, R.E., and Sismeiro, C. A model of Web site browsing behavior estimated on clickstream data. Journal of Marketing Research, 40, 3 (2003), 249-267.

12. Butler, P., and Peppard, J. Consumer purchasing on the Internet: Processes and prospects. European Management Journal, 16, 5 (1998), 600-610.

13. Carmel, E., Crawford, S., and Chen, H. Browsing in hypertext: A cognitive study. IEEE Transactions on Systems, Man, and Cybernetics, 22, 5 (1992), 865-884.

14. Chandra, A., and Krovi, R. Representational congruence and information retrieval: Towards an extended model of cognitive fit. Decision Support Systems, 25, 4 (1999), 271-288.

15. Cohen, J. Statistical Power Analysis for the Behavioral Sciences, 2d ed. Hillsdale, NJ: Lawrence Erlbaum, 1988.

16. Cooper-Martin, E. Effects of information format and similarity among alternatives on consumer choice processes. Journal of the Academy of Marketing Science, 21, 3 (1993), 239-246.

17. Dennis, A.R., and Carte, T.A. Using geographical information systems for decision making: Extending cognitive fit theory to map-based presentation. Information Systems Research, 9, 2 (1998), 194-203.

18. DeSanctis, G. Computer graphics as decision aids: Directions for research. Decision Sciences, 15, 4 (1984), 463-487.

19. Dodds, W.B.; Monroe, K.B.; and Grewal, D. Effects of price, brand, and store information on buyers' product evaluations. Journal of Marketing Research, 28, 3 (1991), 307-319.

20. Fang, X. A hierarchical search history for Web searching. International Journal of $\mathrm{Hu}$ man-Computer Interaction, 12, 1 (2000), 73-88.

21. Forrester Research. Global online trade will climb to $18 \%$ of sales. Cambridge, MA, December 2001 (available at www.forrester.com/ER/Research/Brief/Excerpt/0,1317,13720,FF .html).

22. Gehrke, D., and Turban, E. Determinants of successful website design: Relative importance and recommendations for effectiveness. In R.H. Sprague Jr. (ed.), Proceedings of the Thirty-Second Hawaii International Conference on System Sciences. Los Alamitos, CA: IEEE Computer Society Press, 1999.

23. Glover, E.J., Lawrence, S., Gordon, M.D., Birmingham, W.P., and Giles, C.L. Web search-Your way. Communications of the ACM, 44, 12 (2001), 97-102.

24. Gray, S.H. Using protocol analyses and drawings to study mental model construction during hypertext navigation. International Journal of Human-Computer Interaction, 2, 4 (1990), 359-377.

25. Griffith, D.A.; Krampf, R.F.; and Palmer, J.W. The role of interface in electronic commerce: Consumer involvement with print versus on-line catalogs. International Journal of Electronic Commerce, 5, 4 (Summer 2001), 135-153.

26. Groner, R., and Menz C. The effects of stimulus characteristics, task structures and individual differences on scanning patterns. In R. Groner, G.W. McConkie, and C. Menz (eds.), Eye Movements and Human Information Processing. Amsterdam: North-Holland, 1985, pp. 239-250.

27. Groner, R.; Walder, F.; and Groner, M. Looking at faces: Local and global aspects of scanpaths. In A.G. Gale and F. Johnson (eds.), Theoretical and Applied Aspects of Eye Movement Research. Amsterdam: North-Holland, 1984, pp. 523-533.

28. Hair, J.F.; Anderson, R.E.; Tatham, R.L.; and Black, W.C. Multivariate Data Analysis, 5th ed. Upper Saddle River, NJ: Prentice Hall, 1998.

29. Hearst, M.; Elliott, A.; English, J.; Sinha, R.; Swearingen, K.; and Yee, K.-P. Finding the flow in Web site searching. Communications of the ACM, 45, 9 (2002), 42-49.

30. Higie, R.A., and Sewall, M.A. Using recall and brand preference to evaluate advertising effectiveness. Journal of Advertising Research, 31, 2 (1991), 56-63.

31. Hoffman, D.L., and Novak, T.P. Marketing in hypermedia computer-mediated environments: Conceptual foundations. Journal of Marketing, 60, 3 (1996), 50-68.

32. Hoque, A.Y., and Lohse, G.L. An information search cost perspective for designing interfaces for electronic commerce. Journal of Marketing Research, 36, 3 (1999), 387-394.

33. Hornik, J. Quantitative analysis of visual perception of printed advertisements. Journal of Advertising Research, 20, 6 (1980), 41-48.

34. Hubona, G.S. Mental representation of spatial language. International Journal of Human-Computer Studies, 48, 6 (1998), 705-728. 
35. Janiszewski, C. Preattentive mere exposure effects. Journal of Consumer Research, 20, 3 (1993), 376-392.

36. Janiszewski, C. The influence of display characteristics on visual exploratory search behavior. Journal of Consumer Research, 25, 3 (1998), 290-301.

37. Jarvenpaa, S.L. The effect of task demands and graphical format on information processing strategies. Management Science, 35, 3 (1989), 285-303.

38. Jarvenpaa, S.L, and Todd, P.A. Consumer reactions to electronic shopping on the World Wide Web. International Journal of Electronic Commerce, 1, 2 (Winter 1996-97), 59-88.

39. Kerlinger, F.N. Foundations of Behavioral Research, 3d ed. New York: Harcourt Brace College Publishers, 1992, pp. 241-242.

40. Kim, J., and Yoo, B. Toward the optimal link structure of the cyber shopping mall. International Journal of Human-Computer Studies, 52, 3 (2000), 531-551.

41. Kirk, R.E. Experimental Design: Procedures for the Behavioral Sciences, $3 \mathrm{~d}$ ed. Pacific Grove, CA: Brooks/Cole, 1995.

42. Lohse, G.L., and Spiller, P. Electronic Shopping. Communications of the ACM, 41, 7 (1998), 81-87.

43. Lohse, G.L., and Spiller, P. Quantifying the effect of user interface design features on cyberstore traffic and sales. In C.-M. Karat and A. Lund (eds.), CHI 98: Conference on Human Factors in Computing Systems. New York: ACM Press, 1998, pp. 211-224.

44. Lohse, G.L.; Bellman, S.; and Johnson, E.J. Consumer buying behavior on the Internet: Findings from panel data. Journal of Interactive Marketing, 14, 1 (2000), 15-29.

45. Mandel, N., and Johnson, E.J. When Web pages influence choice: Effects of visual primes on experts and novices. Journal of Consumer Research, 29, 2 (2002), 235-245.

46. Marchionini, G. Information seeking strategies of novices using a full-text electronic encyclopedia. Journal of American Society of Information Science, 40, 1 (1989), 54-66.

47. Marshall, C.; Nelson, C.; and Gardiner, M.M. Design guidelines. In M.M. Gardiner and B. Christie (eds.), Applying Cognitive Psychology to User-Interface Design. New York: Wiley, 1987, pp. 221-278.

48. Mennecke, B.E.; Crossland, M.D.; and Killingsworth, B.L. Is a map more than a picture? The role of SDSS technology, subject characteristics, and problem complexity on map reading and problem solving. MIS Quarterly, 24, 4 (2000), 601-629.

49. Miles, G.E.; Howes, A.; and Davies, A. A framework for understanding human factors in Web-based electronic commerce. International Journal of Human-Computer Studies, 52, 1 (2000), 131-163.

50. Moe, W.W. Buying, searching, or browsing: Differentiating between online shoppers using in-store navigational clickstream. Journal of Consumer Psychology, 13, 1-2 (2003), 29-39.

51. Murphy, J. Surfers and searchers. Cornell Hotel and Restaurant Administration Quarterly, 40, 2 (1999), 84-95.

52. Muter, P., and Maurutto, P. Reading and skimming from computer screens and books: The paperless office revisited? Behaviour and Information Technology, 10, 4 (1991), 257-266.

53. Nielsen, J. Designing Web Usability: The Practice of Simplicity. Indianapolis: New Riders Publishing, 2000.

54. Noton, D., and Stark, L. Eye movements and visual perception. Scientific American, 224, 6 (1971), 34-43.

55. Noton, D., and Stark, L. Scanpaths in saccadic eye movements while viewing and recognizing patterns. Vision Research, 11, 9 (1971), 929-942.

56. Palmer, J.W. Web site usability, design, and performance metrics. Information Systems Research, 13, 2 (2002), 151-167.

57. Palmer, J.W.; Kallio, J.; and Heck, E.V. Online grocery shopping around the world: Examples of key business models. Communications of the AIS, 4, 3 (2000).

58. Park, J., and Kim, J. Contextual navigation aids for two World Wide Web systems. International Journal of Human-Computer Interaction, 12, 2 (2000), 193-217.

59. Pashler, H.E. The Psychology of Attention. Cambridge, MA: MIT Press, 1998.

60. Pereira, R.E. Optimizing human-computer interaction for the electronic commerce environment. Journal of Electronic Commerce Research, 1, 1 (2000), 23-44. 
61. Pieters, R.G.M., and Bijmolt, T.H.A. Consumer memory for television advertising: A field study of duration, serial position, and competition effects. Journal of Consumer Research, 23, 4 (1997), 362-372.

62. Pieters, R.G.M.; Rosbergen, E.; and Wedel, M. Visual attention to repeated print advertising: A test of scanpath theory. Journal of Marketing Research, 36, 4 (1999), 424-438.

63. Rosbergen, E.; Pieters, R.G.M.; and Wedel, M. Visual attention to advertising: A segment-level analysis. Journal of Consumer Research, 24, 3 (1997), 305-314.

64. Rowley, J. Product search in e-shopping: A review and research propositions. Journal of Consumer Marketing, 17, 1 (2000), 20-35.

65. Rowley, J. "Window" shopping and browsing opportunities in cyberspace. Journal of Consumer Behavior, 1, 4 (2001), 369-378.

66. Schubert, P., and Selz, D. Web assessment-Measuring the effectiveness of electronic commerce sites going beyond traditional marketing paradigms. In R.H. Sprague Jr. (ed.), Proceedings of the Thirty-Second Hawaii International Conference on System Sciences. Los Alamitos, CA: IEEE Computer Society Press, 1999, pp. 10-19.

67. Shapiro, S.; Macinnis, D.J.; and Heckler, S.E. The effects of incidental ad exposure on the formation of consideration sets. Journal of Consumer Research, 24, 1 (1997), 94-104.

68. Shaw, M.L., and Shaw, P. Optimal allocation of cognitive resources to spatial locations. Journal of Experimental Psychology: Human Perception and Performance, 3, 2 (1977), 201-211.

69. Singh, S.N.; and Dalal, N.P. Web home pages as advertisements. Communications of the ACM, 42, 8 (1999), 91-98.

70. Sinha, A.P., and Vessey, I. Cognitive fit: An empirical study of recursion and iteration. IEEE Transactions on Software Engineering, 18, 5 (1992), 368-379.

71. Smelcer, J.B., and Carmel, E. The effectiveness of different representations for managerial problem solving: Comparing tables and maps. Decision Sciences, 28, 2 (1997), 391-420.

72. Smith, P.A.; Newman, I.A.; and Parks, L.M. Virtual hierarchies and virtual networks: Some lessons from hypermedia usability research applied to the World Wide Web. International Journal of Human-Computer Interaction, 47, 1 (1997), 67-95.

73. Te'eni, D., and Feldman, R. Performance and satisfaction in adaptive websites: An experiment on searches within a task-adapted website. Journal of the AIS, 2, Article 3 (May 2001).

74. Teo, H.-H.; Oh, L.-B.; Liu, C.; and Wei, K.-K. An empirical study of the effects of interactivity on Web user attitude. International Journal of Human-Computer Studies, 58, 3 (2003), 281-305.

75. Toms, E.G. Understanding and facilitating the browsing of electronic text. International Journal of Human-Computer Studies, 52, 3 (2000), 423-452.

76. Top 10 Web sites by category. Los Angeles Times (October 23, 2000), C4.

77. Umanath, N.S., and Vessey, I. Multiattribute data presentation and human judgment: A cognitive fit perspective. Decision Sciences, 25, 5-6 (1994), 795-824.

78. Umanath, N.S.; Scamell, R.W.; and Das, S.R. An examination of two screen/report design variables in an information recall context. Decision Sciences, 21, 1 (1990), 216-240.

79. Vessey, I. Cognitive fit: A theory-based analysis of the graphs versus tables literature. Decision Sciences, 22, 2 (1991), 219-240.

80. Vessey, I., and Galletta, D. Cognitive fit: An empirical study of information acquisition. Information Systems Research, 2, 1 (1991), 63-85.

81. Wright, P., and Lickorish, A. Proof-reading texts on screen and paper. Behaviour and Information Technology, 2, 3 (1983), 227-235.

82. Yu, B.-M., and Roh, S.-Z. The effects of menu design on information-seeking performance and user's attitude on the World Wide Web. Journal of the American Society for Information Science and Technology, 53, 11 (2002), 923-933.

83. Zhang, H., and Salvendy, G. The implications of visualization ability and structure preview design for Web information search tasks. International Journal of Human-Computer Interaction, 13, 1 (2001), 75-95. 


\section{Appendix A: Calculation of the Competition for Attention}

THE COMPETITION FOR ATTENTION (displayed in the last column of each table below) was calculated for each of the six brands in both list and matrix formats. Following Janiszewski [36]: competition for attention $=$ (square root of the size of the competing object)/(distance between the center of the focal object and the center of the competing object). The total competition for attention that each brand received was calculated by summing the competition for attention from the other five competing brands. And the total levels of competition for attention in both the list and the matrix formats were calculated by summing all the competition for attention that each of the six brands received. A window of $12 \times 18 \mathrm{~cm}$ for product information presentation was assumed in the calculation.

Matrix $($ Total $=23.4)$

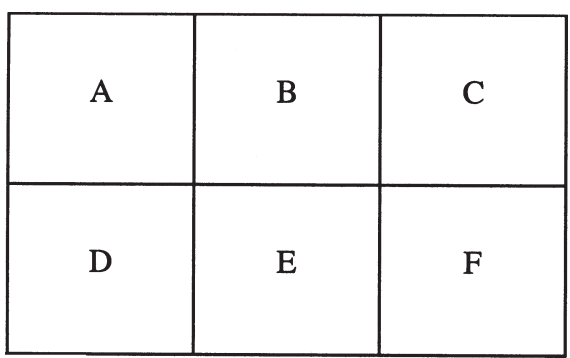

List $($ Total $=52.2)$

\begin{tabular}{|l|}
\hline A \\
\hline B \\
\hline C \\
\hline D \\
\hline E \\
\hline F \\
\hline
\end{tabular}

Notes: A, B, C, D, E, and F each represent an area in which information concerning a particular brand of product is located. As the focus of our calculation is on the relative level of competition for attention between the list and the matrix information format, it should not be unduly affected by the arrangement of detailed product information in each area (especially if the information was kept constant across the two information formats). To save space, two examples (there are a total of 12 screen shots) of the detailed product information arrangement are shown in Figures $3 \mathrm{a}$ and $3 \mathrm{~b}$.

Area A

\begin{tabular}{lccccccr}
\hline & $\begin{array}{c}\text { Size } \\
\left(\mathrm{cm}^{2}\right)\end{array}$ & $\begin{array}{c}\text { Distance } \\
(\mathrm{cm})\end{array}$ & Demand & Area & $\begin{array}{c}\text { Size } \\
\left(\mathrm{cm}^{2}\right)\end{array}$ & $\begin{array}{c}\text { Distance } \\
(\mathrm{cm})\end{array}$ & Demand \\
\hline Area & 36 & 6 & 1.00 & B & 36 & 2 & 3.00 \\
B & 36 & 12 & 0.50 & C & 36 & 4 & 1.50 \\
D & 36 & 6 & 1.00 & D & 36 & 6 & 1.00 \\
E & 36 & 8.5 & 0.70 & E & 36 & 8 & 0.75 \\
F & 36 & 13.4 & 0.45 & F & 36 & 10 & 0.60 \\
& & Total & 3.65 & & & Total & 6.85 \\
\hline
\end{tabular}


Area B

\begin{tabular}{lccccccr}
\hline & $\begin{array}{c}\text { Size } \\
\left(\mathrm{cm}^{2}\right)\end{array}$ & $\begin{array}{c}\text { Distance } \\
(\mathrm{cm})\end{array}$ & Demand & Area & $\begin{array}{c}\text { Size } \\
\left(\mathrm{cm}^{2}\right)\end{array}$ & $\begin{array}{c}\text { Distance } \\
(\mathrm{cm})\end{array}$ & Demand \\
\hline Area & 36 & 6 & 1.00 & A & 36 & 2 & 3.00 \\
C & 36 & 6 & 1.00 & C & 36 & 2 & 3.00 \\
D & 36 & 8.5 & 0.70 & D & 36 & 4 & 1.50 \\
E & 36 & 6 & 1.00 & E & 36 & 6 & 1.00 \\
F & 36 & 8.5 & 0.70 & F & 36 & 8 & 0.75 \\
& & Total & 4.40 & & & Total & 9.25 \\
\hline
\end{tabular}

Area C

\begin{tabular}{lccccccc}
\hline & Size & $\begin{array}{c}\text { Distance } \\
(\mathrm{cm})\end{array}$ & Demand & Area & $\begin{array}{c}\text { Size } \\
\left(\mathrm{cm}^{2}\right)\end{array}$ & $\begin{array}{c}\text { Distance } \\
(\mathrm{cm})\end{array}$ & Demand \\
\hline Area & 36 & 12 & 0.50 & A & 36 & 4 & 1.50 \\
B & 36 & 6 & 1.00 & B & 36 & 2 & 3.00 \\
D & 36 & 13.4 & 0.45 & D & 36 & 2 & 3.00 \\
E & 36 & 8.5 & 0.70 & E & 36 & 4 & 1.50 \\
F & 36 & 6 & 1.00 & F & 36 & 6 & 1.00 \\
& & Total & 3.65 & & & Total & 10.00 \\
\hline
\end{tabular}

Area D

\begin{tabular}{lccccccc}
\hline & $\begin{array}{c}\text { Size } \\
\left(\mathrm{cm}^{2}\right)\end{array}$ & $\begin{array}{c}\text { Distance } \\
(\mathrm{cm})\end{array}$ & Demand & Area & $\begin{array}{c}\text { Size } \\
\left(\mathrm{cm}^{2}\right)\end{array}$ & $\begin{array}{c}\text { Distance } \\
(\mathrm{cm})\end{array}$ & Demand \\
\hline Area & 36 & 6 & 1.00 & A & 36 & 6 & 1.00 \\
A & 36 & 8.5 & 0.70 & B & 36 & 4 & 1.50 \\
C & 36 & 13.4 & 0.45 & C & 36 & 2 & 3.00 \\
E & 36 & 6 & 1.00 & E & 36 & 2 & 3.00 \\
F & 36 & 12 & 0.50 & F & 36 & 4 & 1.50 \\
& & Total & 3.65 & & & Total & 10.00 \\
\hline
\end{tabular}

Area E

\begin{tabular}{lccccccc}
\hline & $\begin{array}{c}\text { Size } \\
\left(\mathrm{cm}^{2}\right)\end{array}$ & $\begin{array}{c}\text { Distance } \\
(\mathrm{cm})\end{array}$ & Demand & Area & $\begin{array}{c}\text { Size } \\
\left(\mathrm{cm}^{2}\right)\end{array}$ & $\begin{array}{c}\text { Distance } \\
(\mathrm{cm})\end{array}$ & Demand \\
Area & 36 & 8.5 & 0.70 & A & 36 & 8 & 0.75 \\
A & 36 & 6 & 1.00 & B & 36 & 6 & 1.00 \\
B & 36 & 8.5 & 0.70 & C & 36 & 4 & 1.50 \\
C & 6 & 1.00 & D & 36 & 2 & 3.00 \\
D & 36 & 6 & 1.00 & F & 36 & 2 & 3.00 \\
F & 36 & Total & 4.40 & & & Total & 9.25 \\
\hline
\end{tabular}




\begin{tabular}{|c|c|c|c|c|c|c|c|}
\hline Area & $\begin{array}{l}\text { Size } \\
\left(\mathrm{cm}^{2}\right)\end{array}$ & $\begin{array}{c}\text { Distance } \\
(\mathrm{cm})\end{array}$ & Demand & Area & $\begin{array}{l}\text { Size } \\
\left(\mathrm{cm}^{2}\right)\end{array}$ & $\begin{array}{c}\text { Distance } \\
(\mathrm{cm})\end{array}$ & Demand \\
\hline A & 36 & 13.4 & 0.45 & $A$ & 36 & 10 & 0.60 \\
\hline B & 36 & 8.5 & 0.70 & B & 36 & 8 & 0.75 \\
\hline C & 36 & 6 & 1.00 & C & 36 & 6 & 1.00 \\
\hline D & 36 & 12 & 0.50 & $\mathrm{D}$ & 36 & 4 & 1.50 \\
\hline \multirow[t]{2}{*}{$E$} & 36 & 6 & 1.00 & $E$ & 36 & 2 & 3.00 \\
\hline & & Total & 3.65 & & & Total & 6.85 \\
\hline
\end{tabular}




\section{Appendix B: Perception Measures}

\section{Cognitive Decision Effort}

PLEASE INDICATE THE DEGREE to which you would agree with the following statements by choosing a number from 1 to 10 , where 1 indicates "strongly disagree" and 10 indicates "strongly agree."

$\begin{array}{cccccccccc}\begin{array}{c}\text { Strongly } \\ \text { disagree } \\ 1\end{array} & 2 & 3 & 4 & 5 & 6 & 7 & 8 & 9 & 10\end{array}$

(The same scale was used for each of the questions below.)

1. To complete the shopping task, using this Web site was very frustrating.

2. To complete the shopping task, using this Web site took too much time.

3. To complete the shopping task, using this Web site required too much effort.

4. To complete the shopping task, using this Web site was too complex.

5. I easily found the information I was looking for.*(R)

6. To complete the shopping task, using this Web site was easy. (R)

\section{Cognitive Convenience}

Please indicate the degree to which you would agree with the following statements by choosing a number from 1 to 10 , where 1 indicates "strongly disagree" and 10 indicates "strongly agree."

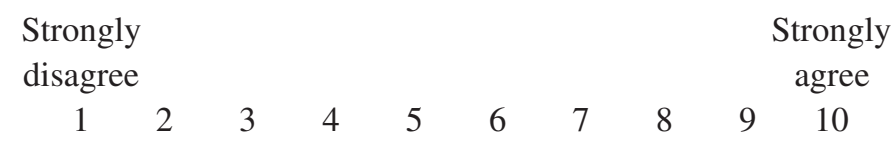

(The same scale was used for each of the questions below.)

1. It is easy for me to move to the target page.

2. It is convenient for me to look for detailed product information.

\section{Attitude Toward Using the Web Site}

Please describe how you felt about the Web site by choosing a number from 1 to 10 for the following statements:

1. I would dislike/like using a Web site built upon this model to perform similar shopping activities.
Dislike
Like

$\begin{array}{llllllllll}1 & 2 & 3 & 4 & 5 & 6 & 7 & 8 & 9 & 10\end{array}$


2. Using a Web site built upon this model to perform similar shopping activities would be pleasant/unpleasant. (R)

\begin{tabular}{cccccccccc} 
Pleasant & & & & & & \multicolumn{4}{c}{ Unpleasant } \\
1 & 2 & 3 & 4 & 5 & 6 & 7 & 8 & 9 & 10
\end{tabular}

*: This item was dropped due to the result of factor analysis.

$\mathrm{R}$ : The items were reverse scaled. 